\title{
Bacteriological Activity of Trovafloxacin, a New Quinolone, against Respiratory Tract Pathogens
}

\author{
J.-C. Pechère, T. D. Gootz
}

\begin{abstract}
The use of established fluoroquinolones, such as ciprofloxacin and ofloxacin, as empirical therapy for the treatment of moderate-to-severe respiratory tract infections is limited by their poor activity against gram-positive and atypical pathogens. Data from in vitro susceptibility studies and in vivo animal protection models suggest that the new fluoroquinolone, trovafloxacin, compared with ciprofloxacin and ofloxacin offers equivalent activity against gram-negative pathogens and improved activity against gram-positive pathogens. In particular, susceptibility data indicate that trovafloxacin is at least 16 -fold more potent than either ciprofloxacin or ofloxacin against penicillin-susceptible and penicillin-resistant strains of Streptococcus pneumoniae. Other susceptible pathogens include Streptococcus pyogenes, vancomycin-susceptible Enterococcus faecalis and the atypical respiratory pathogens Legionella pneumophila, Mycoplasma pneumoniae and Chlamydia pneumoniae. In vivo studies involving models of protection against acute systemic infection and pneumococcal pneumonia in mice, and Legionnaires' disease in guinea pigs, indicate that the antibacterial spectrum observed for trovafloxacin in vitro extends to the in vivo setting. Together, these findings suggest that trovafloxacin may offer clinical efficacy against respiratory pathogens superior to that of ciprofloxacin and of ofloxacin, and may find a useful role as empiric therapy in both the community and hospital setting.
\end{abstract}

\section{Introduction}

High incidences of penicillin resistance [1], escalating $\beta$-lactamase production and poor activity against atypical pathogens are increasingly limiting the use of $\beta$-lactam antibiotics for the empiric treatment of respiratory tract infections. Macrolides have been used as alternative agents, but there is growing concern about the emergence of resistance to this class of antibiotics, particularly with Streptococcus pneumoniae. Clinicians are now searching for other antibiotics that can provide cost-effective, ideally single-agent, empiric therapy for moderate-to-severe community- and hospital-acquired respiratory infections.

J.-C. Pechère (四)

Department of Genetics and Microbiology,

University of Geneva Medical School, Avenue de Champel 9, $\mathrm{CH}-1211$ Geneva 4, Switzerland

T. D. Gootz

Central Research Division, Pfizer Inc, Eastern Point Road, Groton, CT 06340, USA
The established fluoroquinolone antibiotics exhibit excellent activity against a broad spectrum of gramnegative pathogens, resulting in their use as monotherapy for acute exacerbations of chronic bronchitis and as part of a combination therapy for hospitalacquired pneumonia. By contrast, the activity of established fluoroquinolones is only moderate against Streptococcus pneumoniae and Mycoplasma pneumoniae; thus their use as first-line therapy for communityacquired pneumonia is not widely accepted.

There is a need, therefore, for new fluoroquinolones that offer improved activity against gram-positive and atypical respiratory pathogens. Trovafloxacin is a novel fluoronaphthyridone with a similar structure to existing fluoroquinolones. This article reviews the preclinical evaluation of trovafloxacin against respiratory pathogens that are isolated from widely diverse geographical locations. 


\section{Chemical Structure}

Most currently available quinolone antibacterial agents possess the same core structure (Figure 1a). Experience gained during the development of the quinolones has confirmed the importance of the nitrogen at $\mathrm{N}-1$, the ketone at $\mathrm{C}-4$, the carboxylic group at $\mathrm{C}-3$ and the fluoride at C-6 for potent antimicrobial activity. Most of the variation in structure and activity within this family of compounds is derived from substitutions at positions $\mathrm{N}-1$ and C-7 [2]. Trovafloxacin (CP-99,219), a fluoronaphthyridone, while retaining the quinolone core structure, has a combination of structural moieties not found in other fluoroquinolones: a 3-azabicyclo[3.1.0]hexyl substitution at C-7 and a 2,4-difluorophenyl group at the N-1 position (Figure 1b). The nitrogen atom at the C-8 position, which renders trovafloxacin a naphthyridone, appears to be associated with a long elimination half-life [3].

\section{Mode of Action of Trovafloxacin}

Trovafloxacin, in common with the established fluoroquinolones, elicits its bactericidal action by interacting with and inhibiting the action of bacterial DNA gyrase, i.e., topoisomerase II $[4,5]$. A second topoisomerase, topoisomerase IV, appears to be a secondary target for fluoroquinolones in Escherichia coli [6] and Neisseria gonorrhoeae [7], and the primary target for ciprofloxacin and trovafloxacin in Staphylococcus aureus [8], and

a<smiles>[R]c1[X]c2c(c([R])c1F)c(=O)c(C(=O)O)cn2[R]</smiles>

b

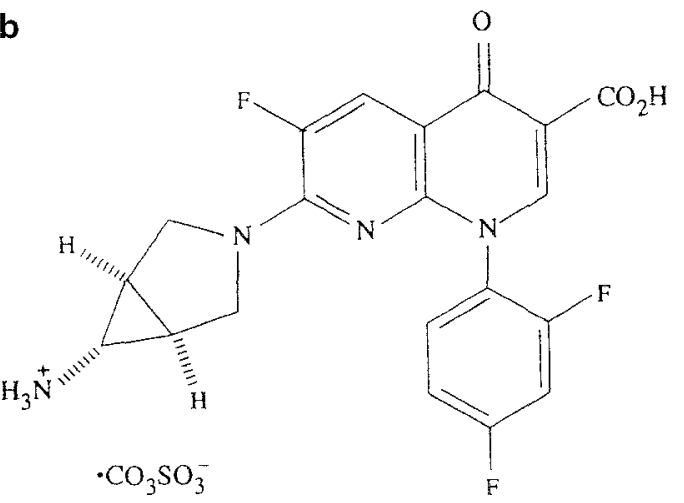

Figure 1 Chemical structures of (a) quinolone antibiotics and (b) trovafhovarin
Streptococcus pneumoniae [9]. The agent does not inhibit eukaryotic topoisomerase II and, therefore, is not cytotoxic towards human cells [10].

\section{Mechanisms of Resistance to Fluoroquinolones}

The dominant factor in the emergence of resistance to fluoroquinolones appears to be mutation of DNA gyrase in gram-negative and of topoisomerase IV in gram-positive organisms [3]. An additional mechanism of resistance includes the presence of efflux transporters [11-13], which actively export fluoroquinolones from within the bacteria. The role of porins and outer membrane permeability is more questionable.

Studies in Streptococcus pneumoniae [9], Staphylococcus aureus [14] and Pseudomonas aeruginosa [15] have indicated that trovafloxacin has a reduced potential to select fluoroquinolone resistance compared with other agents, such as ciprofloxacin.

\section{Antimicrobial Activity in Vitro}

A large number of microbiological studies have evaluated the in vitro susceptibilities of gram-negative, grampositive and atypical respiratory pathogens to trovafloxacin, ciprofloxacin and ofloxacin. Typically, these studies determined, using National Committee for Clinical Laboratory Standards recommended procedures [16], the minimal concentrations of one or more of the antibiotics that inhibit the growth of $90 \%$ of the bacterial isolates studied $\left(\mathrm{MIC}_{90}\right.$ ), enabling median $\mathrm{MIC}_{90}$ values to be calculated.

Gram-Positive Respiratory Pathogens. The in vitro data indicate that trovafloxacin offers inhibitory activity that is markedly superior to that of either ciprofloxacin or ofloxacin against most gram-positive pathogens (Table 1). For both penicillin-susceptible and -resistant (MIC $\geq 0.5 \mathrm{mg} / \mathrm{l}$ ) Streptococcus pneumoniae strains the median $\mathrm{MIC}_{90}$ is $0.12 \mathrm{mg} / \mathrm{l}$, with a maximum recorded MIC of $0.5 \mathrm{mg} / \mathrm{l}$ and is at least 16 fold more potent than either ciprofloxacin or ofloxacin. Maximum MICs of $8 \mathrm{mg} / 1$ were recorded for both ciprofloxacin and ofloxacin. Methicilin-susceptible Staphylococcus aureus is highly susceptible to trovafloxacin (median $\mathrm{MIC}_{90} 0.06 \mathrm{mg} / \mathrm{l}$ ) compared with ciprofloxacin $(0.75 \mathrm{mg} / \mathrm{l})$ and ofloxacin $(0.5 \mathrm{mg} / \mathrm{l})$. Likewise, trovafloxacin is at least 12- and eightfold more potent than ciprofloxacin and ofloxacin, respectively, against methicillin-resistant Staphylococcus aureus, and at least eightfold more potent against ciprofloxacinresistant isolates; the clinical significance of these differences remains to be determined. Superior activity of trovafloxacin against Streptococcus pyogenes has also been detected. Some isolates of enterococci are susceptible in vitro to trovafloxacin. However, this activity is much less in vancomycin-resistant strains $[18]$ and tro- 
Table 1 Comparative in vitro activities of trovafloxacin, ciprofloxacin and ofloxacin against gram-positive respiratory pathogens

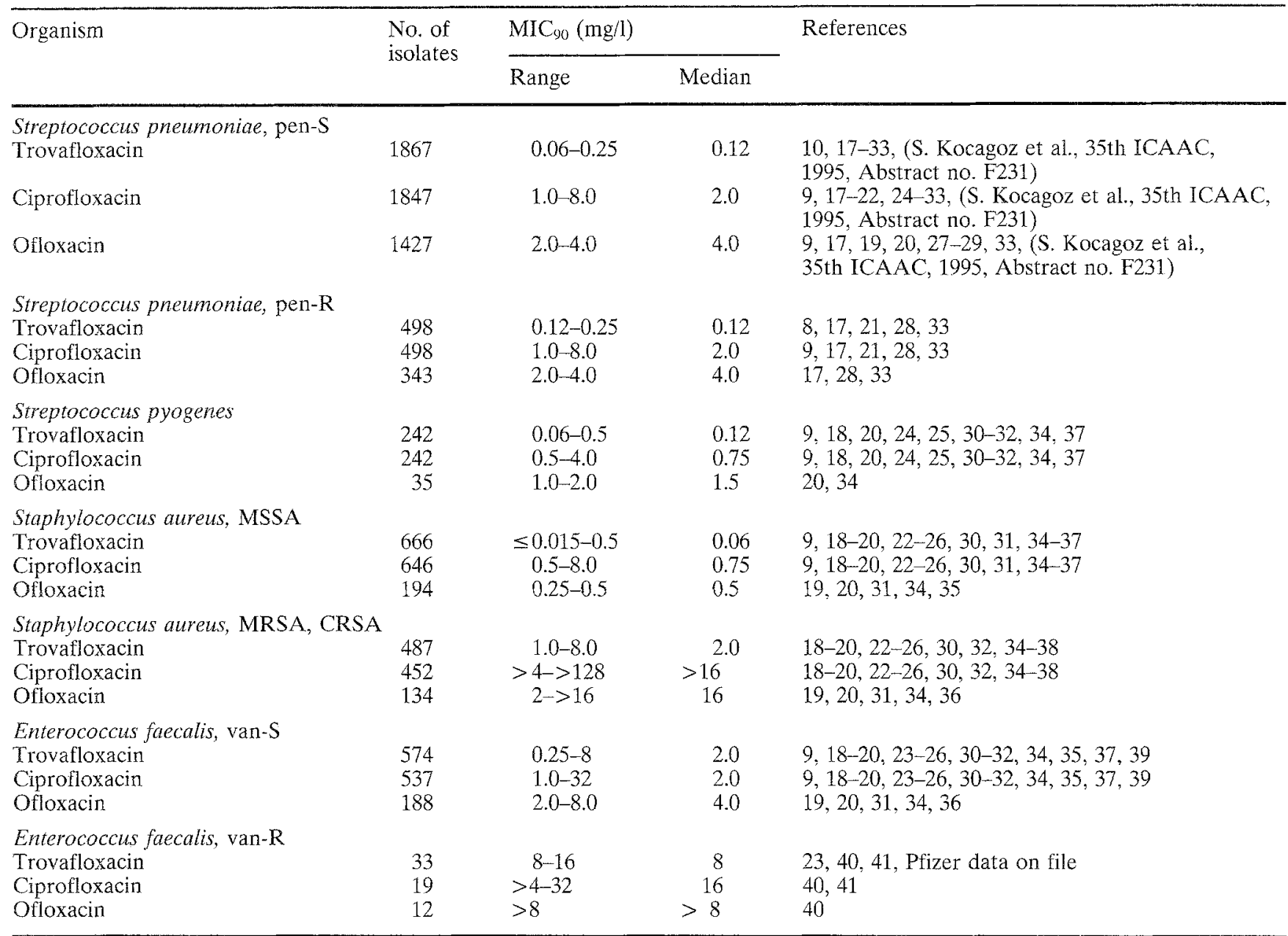

CRSA, ciprofloxacin-resistant Staphylococcus aureus; MRSA, methicillin-resistant Staphylococcus aureus; MSSA, methicillinsusceptible Staphylococcus aureus; pen-R, penicillin-resistant

vafloxacin, in common with other recently developed fluoroquinolones such as sparfloxacin, was unable to reduce intracellular viability of vancomycin-resistant Enterococcus faecium [39, 40].

Gram-Negative Respiratory Pathogens. Overall, trovafloxacin is as active in vitro as ciprofloxacin and more so than ofloxacin against these pathogens (Table 2). Against Haemophilus influenzae, Moraxella catarrhalis and Escherichia coli, for example, the median $\mathrm{MIC}_{90}$ values for trovafloxacin $(0.015,0.03$ and $0.06 \mathrm{mg} / \mathrm{l}$, respectively) are comparable to those of ciprofloxacin and are half those of ofloxacin. The maximum MICs recorded for trovafloxacin were $0.12,0.06$ and $33 \mathrm{mg} / \mathrm{l}$. Against Pseudomonas aeruginosa, trovafloxacin and ciprofloxacin (median $\mathrm{MIC}_{90} 2 \mathrm{mg} / \mathrm{l}$ ) are both fourfold more potent than ofloxacin. The potency of trovafloxacin exceeds that of ciprofloxacin in the case of Stenotrophomonas maltophila.

Against most of the other gram-negative respiratory pathogens tested, trovafloxacin offers an activity gener-
$(\mathrm{MIC} \geq 0.5 \mathrm{mg} / 1) ;$ pen-S, penicillin-susceptible $(\mathrm{MIC}<0.5 \mathrm{mg} / \mathrm{l})$; van-S, vancomycin-susceptible

ally between that of ciprofloxacin and ofloxacin. Overall, the data indicate that the activity of trovafloxacin is comparable to the activities of ciprofloxacin and ofloxacin across a broad spectrum of gram-negative pathogens.

Atypical Respiratory Pathogens. The median $\mathrm{MIC}_{90} \mathrm{~S}$ derived from in vitro susceptibility studies indicate that trovafloxacin is as active as ofloxacin against Chlamydia pneumoniae and is more active against Legionella pneumophila and Mycoplasma pneumoniae (Table 3 ). In vitro studies also show that trovafloxacin is more active than ciprofloxacin against Legionella pneumophila and Mycoplasma pneumoniae.

\section{Animal Models of Infection}

In an acute systemic infection model, mice were infected with one of a range of gram-positive and gramnegative organisms administered via intraperitoneal injection [45]. Each treatment group of ten mice 
Table 2 Comparative in vitro activities of trovafloxacin, ciprofloxacin, and ofloxacin against gram-negative respiratory pathogens

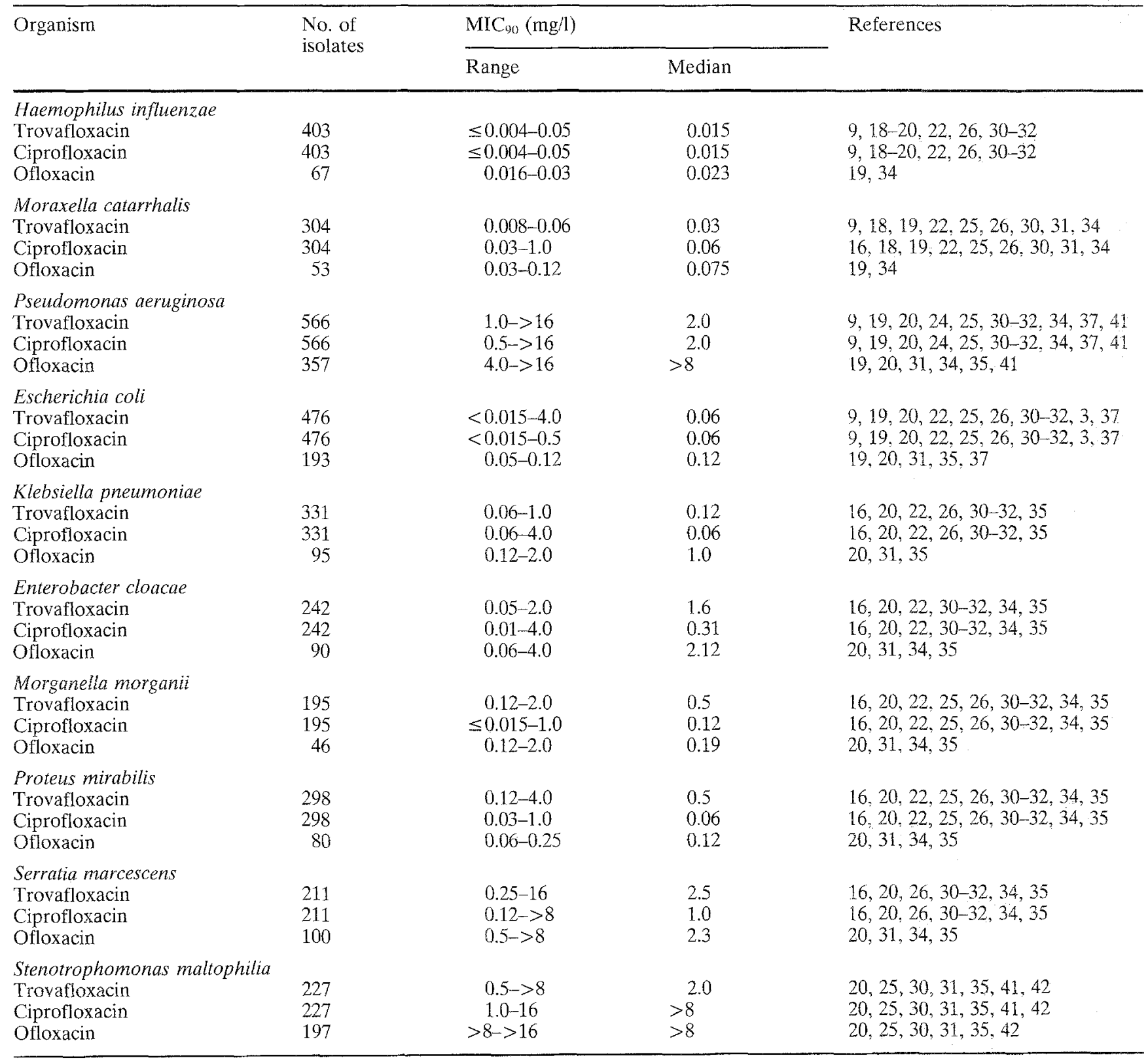

Table 3 Comparative in vitro activities of trovafloxacin, ciprofloxacin, and ofloxacin against atypical respiratory pathogens

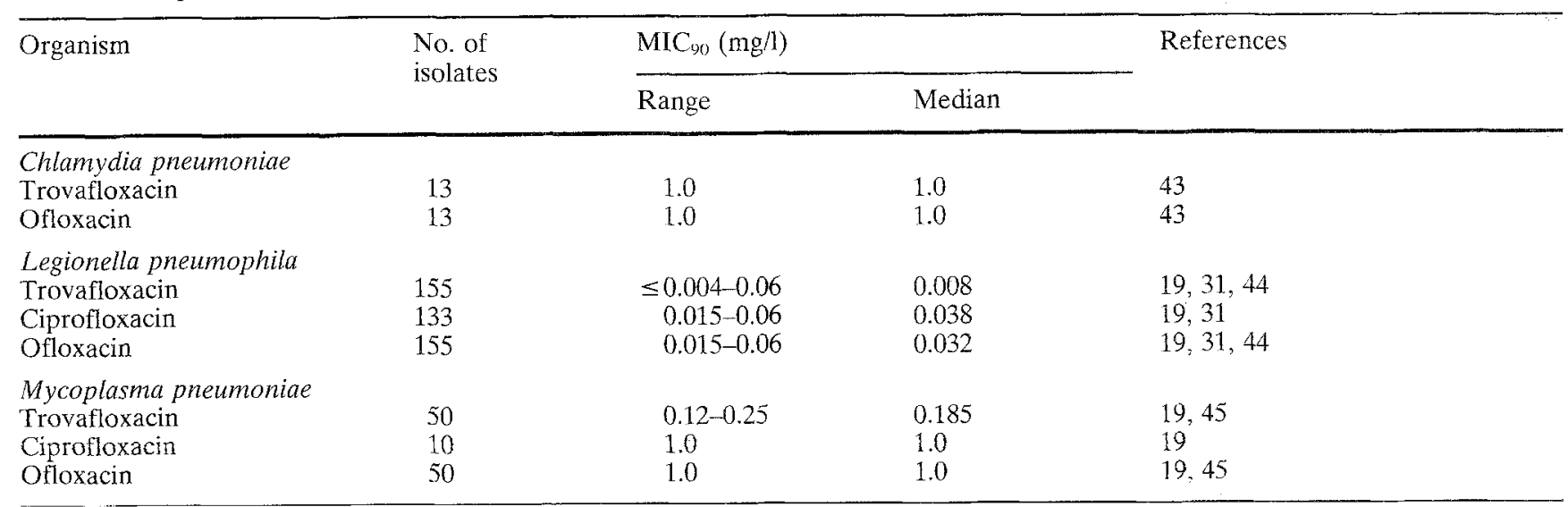


Table 4 In vivo activity of orally-delivered trovafloxacin against gram-positive pathogens in mice [46]

\begin{tabular}{lccc}
\hline Challenge (strain) & \multicolumn{2}{l}{$\mathrm{PD}_{50}(95 \%$ confidence limits, $\mathrm{mg} / \mathrm{kg})$} \\
\cline { 2 - 4 } & Trovafloxacin & Ciprofloxacin & Ofloxacin \\
\hline Streptococcus pneumoniae (02J0025) & $1.3(0.6-2.6)$ & $>50$ & $>50$ \\
Streptococcus pneumoniae (Pocidalo 4241) & $9.7(5.8-16.1)$ & $>50$ & $>13.1(8.2-21.1)$ \\
Staphylococcus aureus (01A0400), MSSA & $2.9(3.7-11.0)$ & $1.1(1.0-3.4)$ & $\mathrm{NA}$ \\
Staphylococcus aureus (01A0129) & $2.0(1.1-3.6)$ & $>50$ & $>50$ \\
Staphylococcus aureus (01A1080) & $42.6(40.8-69.1)$ & $>50$ & $>50$ \\
Staphylococcus aureus (01A1063) & 30 & $3.7(4.8-15.5)$ & $>50$ \\
Streptococcus pyogenes (ATCC12384) & $6.4(1.7-5.4)$ & $>50$ & $>50$ \\
Enterococcus faecalis (03A0131) & & &
\end{tabular}

NA, not available

received an oral dose of antibiotic administered 0.5 and $4 \mathrm{~h}$ after infection. The numbers of mice that survived until day 4 were determined and used to calculate the protective dose for $50 \%$ of the animals $\left(\mathrm{PD}_{50}\right)$.

Gram-Positive Respiratory Pathogens. Trovafloxacin provided effective treatment in the acute systemic infection model [44] and was generally superior to ciprofloxacin or ofloxacin (Table 4). The $\mathrm{PD}_{50}$ values indicate that trovafloxacin was particularly effective against two strains of Streptococcus pneumoniae, whereas both ciprofloxacin and ofloxacin proved ineffective even at the highest dose employed $(50 \mathrm{mg} / \mathrm{kg} /$ day).

Against a methicillin-resistant Staphylococcus aureus strain (01A0129), trovafloxacin and ciprofloxacin appeared to be equally effective. However, data for other Staphylococcus aureus strains highlight clear differences in potency among the fluoroquinolones. Trovafloxacin was more than fourfold more effective than ciprofloxacin against a methicillin-susceptible strain (01A0400) and was the only fluoroquinolone to demonstrate activity against one of the fluoroquinolone-resistant (trovafloxacin $\mathrm{MIC}=3.12 \mathrm{mg} / \mathrm{l}$ ) strains (01A1080). None of the fluoroquinolones exhibited in vivo activity against strain 01A1063, which is highly resistant to fluoroquinolones (trovafloxacin $\mathrm{MIC}=$ $25 \mathrm{mg} / \mathrm{l})$.

The pattern of superior activity for trovafloxacin extends to the other pathogens investigated. Trovafloxacin was nearly threefold more active than ciprofloxacin in protecting mice against Streptococcus pyogenes infection and was effective against Enterococcus faecalis, against which both ciprofloxacin and ofloxacin proved ineffective at the highest dose tested. In these tests, the efficacy observed with trovafloxacin generally paralleled its in vitro potency against the infecting pathogen.

Two additional animal protection studies have demonstrated the relative activities of trovafloxacin, ciprofloxacin and ofloxacin in treating infections caused by
Streptococcus pneumoniae. In one study, two groups of ten mice were infected intranasally with Streptococcus pneumoniae strain Pocidalo 4241 [47]. Oral twice-daily therapy with trovafloxacin or ciprofloxacin was initiated $18 \mathrm{~h}$ after infection and maintained for 3 days. Survivors were monitored over 10 days, after which the $\mathrm{PD}_{50}$ was calculated. The results suggest that trovafloxacin is more potent in vivo than ciprofloxacin. Trovafloxacin protected $90-100 \%$ of the animals with oral therapies of $12.5-50 \mathrm{mg} / \mathrm{kg}$, giving a $\mathrm{PD}_{50}$ of $2.1 \mathrm{mg} / \mathrm{kg}$. In contrast, ciprofloxacin protected only $20-30 \%$ of challenged animals at doses of $75-100 \mathrm{mg} / \mathrm{kg}$.

A second study employed a similar mouse pneumonia model to compare the activities of trovafloxacin, ciprofloxacin and ofloxacin against one penicillin-susceptible Streptococcus pneumoniae strain (Pocidalo 4241) in immunocompetent mice and three penicillin-resistant isolates in leucopenic mice [48]. Therapy began $6 \mathrm{~h}$ and $3 \mathrm{~h}$, respectively, after infection and involved the administration of two subcutaneous doses per day for 3 days. Untreated, control mice died by day 3 post-challenge in this model. Survival rates with trovafloxacin were significantly greater than with ciprofloxacin or ofloxacin. A once-daily $25 \mathrm{mg} / \mathrm{kg}$ dose of trovafloxacin protected $91 \%$ of the mice infected with the penicillinsusceptible strain 4241 and $66-100 \%$ of mice infected with penicillin-resistant strains. By comparison, in the case of ciprofloxacin, the next most effective agent, a dose of $100 \mathrm{mg} / \mathrm{kg}$ protected only $23 \%$ and $58 \%$ of mice, respectively.

An indication of the greater clinical potential of trovafloxacin against Streptococcus pneumoniae is also provided by its superior distribution into the lung tissues compared with ciprofloxacin. Girard et al. [46] found that, in mice infected with strain 4241, the maximum concentration of trovafloxacin in lung tissue was at least twice that of ciprofloxacin, and that the half-life of trovafloxacin was over threefold greater. Consequently, the area under the lung concentration-time curve for trovafloxacin was nearly sixfold greater than for ciprofloxacin. 
Table 5 In vivo activity of orally-delivered trovafloxacin against gram-negative pathogens in mice [46]

\begin{tabular}{|c|c|c|c|}
\hline \multirow[t]{2}{*}{ Challenge (strain) } & \multicolumn{3}{|c|}{$\mathrm{PD}_{50}(95 \%$ confidence limits, $\mathrm{mg} / \mathrm{kg})$} \\
\hline & Trovafloxacin & Ciprofloxacin & Ofloxacin \\
\hline Enterobacter cloacae (67B0153) & $12.5(6.7-23.1)$ & $18.1(7.6-42.8)$ & NA \\
\hline Escherichia coli (51A0266) & $2.3(0.8-6.1)$ & $<0.8$ & $<0.8$ \\
\hline Klebsiella pneumoniae (ATCC 43816) & $1.1(0.4-1.8)$ & $2.5(1.8-3.3)$ & NA \\
\hline Morganella morganii (97A0096) & $16.8(7.6-37.3)$ & $4.6(2.3-9.2)$ & NA \\
\hline Pseudomonas aeruginosa (52A0266) & $6.5(3.5-12.0)$ & $1.2(0.5-2.6)$ & $1.9(0.8-4.7)$ \\
\hline Proteus mirabilis (57C0175) & $5.6(3.0-10.3)$ & $6.9(3.8-12.9)$ & $17.5(7.7-39.8)$ \\
\hline
\end{tabular}

NA, not available

Gram-Negative Respiratory Pathogens. The acute systemic infection model that established superior potency of trovafloxacin against gram-positive respiratory pathogens has also shown that trovafloxacin, ciprofloxacin and ofloxacin offer broadly comparable in vivo activities against important gram-negative respiratory pathogens [46]. Trovafloxacin was slightly more active against Enterobacter cloacae and Klebsiella pneumoniae than ciprofloxacin, but slightly less so than ciprofloxacin and ofloxacin against Escherichia coli and Pseudomonas aeruginosa, and markedly less effective than ciprofloxacin against Morganella morganii (Table 5). The activity of trovafloxacin against Proteus mirabilis was slightly higher than that of ciprofloxacin and markedly higher than that of ofloxacin.

Atypical Respiratory Pathogens. The in vivo activity of trovafloxacin against Legionella pneumophila has been explored and compared with that of ofloxacin in an animal model featuring lethal lung infections with this atypical pathogen [44]. Guinea pigs infected intratracheally with Legionella pneumophila serogroup 1 strain F889 received a single dose of trovafloxacin $(7.5 \mathrm{mg} /$ $\mathrm{kg})$, ofloxacin $(10 \mathrm{mg} / \mathrm{kg})$ or saline, administered intraperitoneally once daily for 5 days.

All guinea pigs treated with trovafloxacin or ofloxacin survived 14 days after infection, whereas none of the control guinea pigs survived more than 5 days. No significant differences in lung histology were noted between the trovafloxacin- and ofloxacin-treated animals who survived. Only two of the seven lung samples from the trovafloxacin treatment group were positive for Legionella pneumophila, compared with three of the seven lung samples from the ofloxacin group. The major difference observed between the treatment groups was slower weight gain in the trovafloxacin group, which could have been attributable to lower initial weights in this group before infection [44].

A similar study involving the same experimental model has shown that trovafloxacin $(5 \mathrm{mg} / \mathrm{kg} / \mathrm{day})$ completely eradicated Legionella pneumophila from the lungs and spleen in all animals after 4-5 days of treatment and that Legionella could not be recovered after 28 days (E. Millas et al., 36th ICAAC, 1996, Abstract no. E76).

The in vitro susceptibility data, combined with better in vivo activity than either ciprofloxacin or ofloxacin, led Edelstein et al. [44] to conclude that trovafloxacin is one of the most active antimicrobial agents tested against Legionella species, being more effective than ciprofloxacin and other antibiotics such as azithromycin, erythomycin, clavulanic acid and tazobactam.

\section{Tissue and Intracellular Penetration of Trovafloxacin}

Positron emission tomography performed in healthy volunteers revealed that the peak concentration of trovafloxacin in lung following a $200 \mathrm{mg}$ dose was $22.5 \pm 7.1 \mu \mathrm{g} / \mathrm{g}$ [A.J. Fischman et al. 37th ICAAC, 1997, Abstract no. A68]. Edelstein et al. [44] showed that the maximum concentration of trovafloxacin in guinea pig alveolar macrophages in vitro was 28 -fold greater than the concentration in extracellular fluid. Concentration in serum, alveolar macrophages, epithelial lining and bronchial mucosa of $1.01 \mathrm{mg} / \mathrm{kg}, 0.37,10.23$ and $0.93 \mathrm{mg} / \mathrm{l}$, respectively, have been recorded $24 \mathrm{~h}$ after a single oral dose of $200 \mathrm{mg}$ trovafloxacin in humans [47]. These concentrations exceeded even the highest median $\mathrm{MIC}_{90}$ values of respiratory pathogens presented in Tables $1-3$, and should be sufficiently high to ensure bacterial eradication.

\section{Conclusions}

Fluoroquinolones comprise just one of many classes of antimicrobial agents used to treat the gamut of community- and hospital-acquired respiratory tract infections in humans. Although ciprofloxacin and ofloxacin find some use in the treatment of acute exacerbations of chronic bronchitis and in combination with other agents, for hospital-acquired pneumonia, their more widespread use for community-acquired pneumonia is limited by their relatively poor activity against pneumococci and atypical pathogens. Further, the use of pres- 
ently marketed fluoroquinolones has been accompanied by the emergence of fluoroquinolone-resistant Staphylococcus aureus and Streptococcus pneumoniae strains. Therefore, a demand exists for new antibiotics with broad-spectrum activities that enable them to be prescribed with confidence for empiric monotherapy.

The results of in vitro and in vivo studies indicate that trovafloxacin offers activity comparable to that of ciprofloxacin and ofloxacin against gram-negative respiratory pathogens together with superior activity against gram-positive organisms. Trovafloxacin is also active against the atypical respiratory pathogens. Its extensive activity against pathogens commonly implicated in respiratory infections, together with its ability to achieve concentrations in respiratory tissue far in excess of MICs, suggests that trovafloxacin may provide effective empiric treatment of community- and hospital-acquired infections, including sinusitis, acute exacerbations of chronic bronchitis, community- and hospital-acquired pneumonia, and atypical pneumonia.

\section{References}

1. Baquero F: Epidemiology and management of penicillinresistant pneumococci. Current Opinion in Infectious Diseases (1996) 9:372-379

2. Brighty KE, Gootz TD: The chemistry and biological profile of trovafloxacin. Journal of Antimicrobial Chemotherapy (1997) 39, Supplement B:1-14

3. Gootz TD, Brighty KE: Fluoroquinolone antibacterials: SAR, mechanism of action, resistance, and clinical aspects. Medicinal Research Reviews (1996) 16:433-486

4. Wiedemann B, Heisig P: Mechanisms of quinolone resistance. Infection (1994) 22, Supplement 2:73-79

5. Hooper DC, Wolfson JS: Mechanisms of quinolone action and bacterial killing. In: Hooper DC, Wolfson JS (eds): Quinolone antimicrobial agents. American Society for Microbiology, Washington, DC (1993), pp 53-75

6. Hoshino K, Kitamura A, Morrissey I, Sato K, Kato J, Ikeda $\mathrm{H}$ : Comparison of inhibition of Escherichia coli topoisomerase IV by quinolones with DNA gyrase inhibition. Antimicrobial Agents and Chemotherapy (1994) 38:2623-2627

7. Belland RJ, Morrisson SG, Ison C, Huang WM: Neisseria gonorrhoeae acquires mutations in analogous regions of gyrA and $\operatorname{par} C$ in fluoroquinolone-resistant isolates. Molecular Microbiology (1994) 14:371-380

8. Ferrero L, Cameron B, Crouzet $\mathrm{J}$ : Analysis of gyr $A$ and $g r l A$ mutations in stepwise-selected ciprofloxacin-resistant mutants of Staphylococcus aureus. Antimicrobial Agents and Chemotherapy (1995) 39:1554-1558

9. Gootz TD, Zaniewski R, Haskell S, Schmieder B, Tankovic J, Girard D, Courvalin P, Polzer RJ: Activity of the new fluoroquinolone trovafloxacin (CP-99,219) against DNA gyrase and topoisomerase IV mutants of Streptococcus pneumoniae selected in vitro. Antimicrobial Agents and Chemotherapy (1996) 40:2691-2697

10. Gootz TD, Brighty KE, Anderson MR, Schmeider BJ, Haskell SL, Sutcliffe JA, Castaldi MJ, McGuirk PR: In vitro activity of CP-99,219, a novel 7-(3-azabicyclo[3.1.0]hexyl)naphthyridone antimicrobial. Diagnostic Microbiology and Infectious Disease (1994) 19:235-243
11. Cohen SP, Hachler H, Levy SB: Genetic and functional analysis of the multiple antibiotic resistance (mar) locus in Escherichia coli. Journal of Bacteriology (1993) $175: 1484-1492$

12. Kaatz GW, Seo SM, Ruble CA: Mechanisms of fluoroquinolone resistance in Staphylococcus aureus. Journal of Infectious Diseases (1991) 163:1080-1086

13. Trucksis M, Wolfson JS, Hooper DC: A novel locus conferring fluoroquinolone resistance in Staphylococcus aureus. Journal of Bacteriology (1991) 173:5854-5860

14. Barry AL, Brown SD, Fuchs PC: In-vitro selection of quinolone-resistant staphylococcal mutants by a single exposure to ciprofloxacin or trovafloxacin (CP-99,219). Journal of Antimicrobial Chemotherapy (1996) 38:324-327

15. Köhler T, Michéa-Hamzehpoor M, Plésiat $\mathrm{P}$, Kahr AL, Pechère J-C: Differential selection of multidrug efflux systems of quinolones in Pseudomonas aeruginosa. Antimicrobial Agents and Chemotherapy (1997) 41:2540-2543

16. National Committee for Clinical Laboratory Standards: Standard methods for dilution antimicrobial susceptibility test for bacteria that grow aerobically. Approved standard M7A3. NCCLS, Villanova, PA (1990)

17. Olsson-Liljequist B, Hoffman BM, Hedlund J: Activity of trovafloxacin against blood isolates of Streptococcus pneumoniae in Sweden. European Journal of Clinical Microbiology \& Infectious Diseases (1996) 15:671-675

18. Sefton AM, Maskell JP, Rafay AM, Whiley A, Williams JD: The in-vitro activity of trovafioxacin, a new fluoroquinolone against gram-positive bacteria. Journal of Antimicrobial Chemotherapy (1997) 39, Supplement B:57-62

19. Felmingham D, Robbins MJ, Ingley K, Mathias I, Bhogal H, Leakey A, Ridgway GL, Grüneberg RN: In-vitro activity of trovafloxacin (CP-99,219), a new fluoroquinolone, against recent clinical isolates. Journal of Antimicrobial Chemotherapy (1997) 39, Supplement B:43-49

20. Rolston KVI, Ho DH, LeBlanc B, Streeter H, Dvorak T: Invitro activity of CP-99,219, a novel azabicyclo-naphthyridone, against clinical bacterial isolates from patients with cancer. Journal of Antimicrobial Chemotherapy (1997) 39, Supplement $B: 15-22$

21. Urbásková P, Trupl J, Hupková H, Appelbaum PC, Jacobs MR: In vitro susceptibility of pneumococci to trovafloxacin, penicillin $\mathrm{G}$, and other antimicrobial agents in the Czech Republic and Slovakia. European Journal of Clinical Microbiology \& Infectious Diseases (1996) 15:686-688

22. Crokaert F, Aoun M, Duchateau V, Grenier P, Vandermies A, Klastersky J: In vitro activity of trovafloxacin (CP-99,219), sparfloxacin, ciprofloxacin, and fleroxacin against respiratory pathogens. European Journal of Clinical Microbiology \& Infectious Diseases (1996) 15:696-698

23. Shonekan D, Handwerger S, Mildvan D: Comparative invitro activities of RP59500 (quinupristin/dalfopristin), CL 329.998, CL331,002, trovafloxacin, clinafloxacin, teicoplanin and vancomycin against gram-positive bacteria. Journal of Antimicrobial Chemotherapy (1997) 39:405-409

24. Eliopoulos GM, Klimm K, Eliopoulos CT, Ferraro MJ, Moellering RC Jr: In vitro activity of CP-99,219, a new fluoroquinolone against clinical isolates of gram-positive bacteria. Antimicrobial Agents and Chemotherapy (1993) 37:366-370

25. Child J, Andrews J, Boswell F, Brenwald N, Wise R: The invitro activity of CP-99,219, a new naphthyridone antimicrobial agent: a comparison with fluoroquinolone agents. Journal of Antimicrobial Chemotherapy (1995) 35:869-876

26. Verbist L, Verhaegen $\mathbf{J}$ : In vitro activity of trovafloxacin versus ciprofloxacin against clinical isolates. European Journal of Clinical Microbiology \& Infectious Diseases (1996) $15: 683-685$

27. Thomson KS, Chartrand SA, Sanders CC, Block SL: Trovafloxacin, a new fluoroquinolone with potent activity against Streptococcus pneumoniae. Antimicrobial Agents and Chemotherapy (1997) 41:478-480 
28. Klugman $\mathbf{K}$, Wasas A: In-vitro activity of the fluoroquinolone trovafloxacin against penicillin-susceptible and -resistant Streptococcus pneumoniae. Journal of Antimicrobial Chemotherapy (1995) 36:873-874

29. Pankuch GA, Jacobs MR, Appelbaum PC: Activity of CP99,219 compared with DU-6859a, ciprofloxacin, ofloxacin, levofloxacin, lomefloxacin, tosulfloxacin, sparfloxacin, and grepafloxacin against penicillin-susceptible and -resistant pneumococci. Journal of Antimicrobial Chemotherapy (1995) $35: 230-232$

30. Neu $\mathrm{HC}$, Chin $\mathrm{N}$ : In vitro activity of the new fluoroquinolone CP-99,219. Antimicrobial Agents and Chemotherapy (1994) $38: 2615-2622$

31. Briggs-Gooding $B$, Jones RN: In vitro antimicrobial activity of CP-99,219, a novel azabicyclo-naphthyridone. Antimicrobial Agents and Chemotherapy (1993) 37:349-353

32. Cunha BA, Qadri SMH, Ueno Y, Walters EA, Domenico P: Antibacterial activity of trovafloxacin (CP-99,219) against nosocomial gram-positive and gram-negative isolates. Journal of Antimicrobial Chemotherapy (1997) 39, Supplement B: 29-34

33. Fuchs PC, Barry AL, Brown SD: Tentative interpretative criteria for testing the susceptibility of Streptococcus pneumoniae to eight fluoroquinolones. Diagnostic Microbiology and Infectious Disease (1996) 26:23-27

34. Fuchs PC, Barry AL, Brown SD, Sewell DL: In vitro activity and selection of disk content for disk diffusion susceptibility tests with trovafloxacin. European Journal of Clinical Microbiology \& Infectious Diseases (1996) 15:678-682

35. Dembry LM, Farrell PA, Orcutt DR, Gerrity LA, Andriole VT: In-vitro activity of trovafloxacin (CP-99,219 against sensitive and resistant aerobic bacteria using the standard microdilution broth method and E-test. Journal of Antimicrobial Chemotherapy (1997) 39, Supplement B:35-42

36. Mulazimoglu L, Drenning SD, Yu VL: In vitro activities of two novel oxazolidinones (U100592 and U100766), a new fluoroquinolone (trovafloxacin), and dalfopristin-quinupristin against Staphylococcus aureus and Staphylococcus epidermidis. Antimicrobial Agents and Chemotherapy (1996) 40:2428-2430

37. Coque TM, Singh KV, Murray BE: Comparative in-vitro activity of the new fluoroquinolone trovafloxacin (CP-99,219) against gram-positive cocci. Journal of Antimicrobial Chemotherapy (1996) 37:1011-1016

38. Jones RN: In vitro antimicrobial activity of CP-99,219-99, a new 7-azabicyclonaphthyridone. Drugs (1995) 49, Supplement 21:205-207

39. Cormican MG, Jones RN: In-vitro activity of trovafloxacin (CP-99,219) tested by two methods against 150 vancomycinresistant enterococcal isolates. Journal of Antimicrobial Chemotherapy (1996) 37:847-849
40. Freeman C, Robinson A, Cooper B, Mazens-Sullivan M, Quintiliani $R$, Nightingale $C$ : In vitro antimicrobial susceptibility of glycopeptide-resistant enterococci. Diagnostic Microbiology and Infectious Disease (1995) 21:47-50

41. Visalli MA, Bajaksouzian S, Jacobs MR, Appelbaum PC: Comparative activity of trovafloxacin, alone and in combination with other agents, against gram-negative nonfermentative rods. Antimicrobial Agents and Chemotherapy (1997) 41:1475-1478

42. Fass RJ, Barnishan I, Solomon MC, Ayers LW: In vitro activities of quinolones, $\beta$-lactams, tobramycin and trimethoprim-sulfamethoxazole against nonfermentative gram-negative bacilli. Antimicrobial Agents and Chemotherapy (1996) 40:1412-1418

43. Roblin PM, Kutlin A, Hammerschlag MR: In vitro activity of trovafloxacin against Chlamydia pneumoniae. Antimicrobial Agents and Chemotherapy (1997) 41:2033-2034

44. Edelstein PH, Edelstein MAC, Ren J, Polzer R, Gladue RP: Activity of trovafloxacin (CP-99,219) against Legionella isolates: in vitro activity, intracellular accumulation and killing in macrophages, and pharmacokinetics and treatment of guinea pigs with $L$. pneumophila pneumonia. Antimicrobial Agents and Chemotherapy (1996) 40:314-319

45. Kenny GE, Cartwright FD: Susceptibilities of Mycoplasma pneumoniae, Mycoplasma hominis and Creaplasma urealyticum to a new quinolone, trovafloxacin (CP-99,219). Antimicrobial Agents and Chemotherapy (1996) 40:1048-1049

46. Girard AE, Girard D, Gootz TD, Faiella JA. Cimochowski CR: In vivo efficacy of trovafloxacin (CP-99,219), a new quinolone with extended activities against gram-positive pathogens, Streptococcus pneumoniae and Bacteroides fragilis. Antimicrobial Agents and Chemotherapy (1995) 39:2210-2216

47. Andrews JM, Honeybourne D, Brenwald NP, Bannerjee D, Iredale M, Cunningham D, Wise R: Concentrations of trovafloxacin in bronchial mucosa, epithelial lining fluid, alveolar macrophages and serum after administration of single or multiple oral doses to patients undergoing fibre-optic bronchoscopy. Journal of Antimicrobial Chemotherapy (1997) $39: 797-802$

48. Bedos J-P, Rieux V, Bauchet J, Muffat-Joly M, Carbon C, Azoulay-Dupuis: Efficacy of trovafloxacin against penicillinsusceptible and multiresistant strains in a mouse pneumonia model. Antimicrobial Agents and Chemotherapy (1998) $42: 862-867$ 